\title{
0 esporte no cinema de Portugal
}

\author{
Victor Andrade de Melo
}

https://doi.org/10.5628/rpcd.08.01.157
Universidade Federal do Rio de Janeiro

Brasil

\section{ABSTRACT \\ The sport in the Portugal's cinema}

This article has for objective to present a panorama of the presence of the sport in the history of the Portuguese cinema. It is an important research for its potential in contributing to extend our understanding of the development of the sport in Portugal, since the dialogue with an important typical language of modernity, an expression of the socialcultural formation of the country: the cinema. For reach of the objective it had been analyzed synopses/techniques dates of 703 films produced between 1896 and 2006. It was possible to found 32 films in which the sport was represented, divided in: 12 where it is the central subject; 7 where it occupies place of importance, despite it is not the central subject; e 13 where only it is cited.

Key-words: sport history, sport sociology, cinema
Palavras-chave: história do esporte, sociologia do esporte, cinema 


\section{INTRODUÇÃO}

No mês de setembro de 1896, cerca de um ano e meio depois das primeiras exibições públicas cinematográficas da história (realizadas em Paris) e seis meses após as pioneiras sessões de Portugal (que tiveram lugar em Lisboa), Aurélio de Paz Reis posicionou uma câmera na porta principal da Fábrica Confiança (sediada na cidade do Porto) e gravou imagens de operários a caminho do almoço.

Provavelmente Reis estava inspirado por um dos primeiros filmes produzidos pelos irmãos Auguste e Louis Lumière ${ }^{1}$. Também o incentivava o desejo de contribuir para a modernização da sociedade portuguesa naquele turbulento fin-de-siècle europeu.

Graças às acções de Reis, Portugal entrou bem cedo para o grupo de países que deram início à construção de uma cinematografia nacional, no mesmo ano em que o Brasil e antes de outros hoje reconhecidos por sua produção, como a Itália e a Espanha. Se hodiernamente o cinema português não é comummente citado entre os principais do mundo, a não ser pelo sempre lembrado Manoel de Oliveira, isso não tem relação com sua trajectória ou com sua qualidade, mas sim com questões de natureza económica e cultural.

Independente de sua repercussão internacional, indubitavelmente a cinematografia portuguesa é uma expressão da formação sócio-cultural do país. Nos filmes pode-se identificar representações ${ }^{2}$ das múltiplas dimensões da história de Portugal, tanto nos enredos (reflexos de importantes elementos constitutivos da cultura lusa em seu quadro de tensões) quanto nos aspectos técnicos e estéticos, ambos expressando os desafios e as contradições da construção da idéia de nação. Não é equivocado afirmar, por exemplo, que estão presentes em muitas películas as peculiaridades da inserção de Portugal no cenário europeu (inclusive os relacionamentos, por vezes tensos, com Espanha e Inglaterra) e mundial (onde se destaca a relação com as hoje ex-colónias africanas e com o Brasil).

Assim sendo, se as diversas dimensões culturais portuguesas (tanto em seu sentido mais estrito, as manifestações, quanto em seu sentido mais amplo, os valores e sensibilidades que norteiam a organização social) são representadas pelos cineastas em suas produções, não seria diferente com o esporte, esse importante fenómeno cultural da modernidade, que tanta articulação possui com o próprio desenvolvimento da linguagem cinematográfica no decorrer do século $\mathrm{XX}^{(3)}$.

Este artigo tem por objectivo apresentar um panorama da presença do esporte no cinema português, com ênfase nos longas-metragem, tanto de carácter documental quanto de ficção. Para melhor compor o quadro de inserção da prática esportiva nas películas, apresentamos também algumas informações sobre os primeiros curtas-metragem, produzidos ainda no período não sonoro.

Para alcance do objectivo, foi realizada uma revisão da literatura e uma análise das sinopses/fichas técnicas das películas portuguesas produzidas entre os anos de 1896 e 2006, fazendo uso dos dados disponíveis em:

a) Cinemateca Portuguesa, cujo banco foi consultado pela internet (http://www.cinemateca.pt) e em duas visitas presenciais ${ }^{3}$;

b) Instituto do Cinema, Audiovisual e Multimedia de Portugal, cujo banco foi consultado pela internet (http://www.icam.pt);

c) estudo de M. Félix Ribeiro(4), sobre os primórdios do cinema português;

d) estudo de José de Matos-Cruz(5), sobre os longasmetragem portugueses;

e) estudo de José de Matos-Cruz(6), sobre toda a produção cinematográfica de Portugal;

f) catálogo sobre cinema africano, produzido pela

Cinemateca Portuguesa( 7 ;

g) base da Associação para Promoção do Cinema Português (http://www.amordeperdicao.pt);

h) sítios diversos de informação jornalística, para acessar informações sobre filmes lançados entre os anos de 2000 e 2006.

Foi possível analisar os dados de 703 longas-metragem, sendo encontrados 32 nos quais a prática esportiva está de alguma forma representada: em 12, o esporte é o tema central (lista A); em 7, ocupa lugar de importância, ainda que não seja o tema central (lista B); em 13, é apenas citado (lista C). É necessário fazer algumas ressalvas acerca desse procedimento metodológico. Como não sabemos todos os interesses dos pesquisadores futuros, não nos interessa mapear somente os filmes onde o esporte é o assunto central. Uma breve cena pode 
ser bastante útil para certas investigações; um personagem coadjuvante pode ser esclarecedor de uma representação ao seu redor construída. Por isso fazemos uso das três listas, ampliando o alcance do mapeamento e já previamente indicando aos interessados o "grau" de presença da prática esportiva na trama.

A catalogação, todavia, somente seria absolutamente completa se houvesse a possibilidade de assistir todos os filmes, o que é impossível já que a maior parte não está disponível para o mercado doméstico (VHS ou DVD), não é facilmente acessível em cinematecas/cineclubes ou mesmo não possui mais cópias preservadas, só havendo registos jornalísticos acerca de sua existência. Tendo em vista essa impossibilidade, as sinopses/fichas técnicas acabam sendo o recurso mais operacional.

Logo, os dados apresentados são sempre provisórios, já que: a) não é incomum com o decorrer do tempo encontrarmos novas cenas, conforme surgem oportunidades de assistir filmes raros, cujas sinopses não continham referências ao esporte; b) as próprias cinematecas constantemente actualizam seus bancos, quando descobrem películas antigas não catalogadas; c) além disso, há sempre novos lançamentos a cada ano.

Deve-se ressaltar que, mesmo com esses limites, o uso das sinopses/fichas técnicas já se mostrou bastante produtivo quando realizamos trabalho semelhante com a cinematografia brasileira(8).

Cremos que este estudo se justifica por seu potencial em contribuir para ampliar o entendimento sobre a prática esportiva em Portugal, desvendando sua presença por entre as teias e redes sociais, no diálogo com outras linguagens; ou, como temos denominado no âmbito do projeto "Esporte e Arte: diálogos" (http://www.anima.eefd.ufrj.br/esportearte/), para promover uma "arqueologia social" do fenómeno esportivo.

Há ainda outra motivação: a perspectiva de futuramente estabelecer uma análise comparada entre Brasil e Portugal. Uma das chaves para entender a constituição de uma cultura lusofônica, algo fundamental no cenário geopolítico actual, no sentido de estabelecimento de alianças estratégicas mais eficazes, é ampliar nossa compreensão sobre nossas semelhanças e dissemelhanças. Parece interessante, assim, empreender esforços não só de justaposição de olhares, mas também de implemento de comparações mais profundas. No decorrer deste artigo, faço alguns apontamentos comparativos, ainda que fique para uma próxima oportunidade o aprofundamento dessa perspectiva metodológica4.

\section{PRIMEIRAS CENAS: 0 CARÁTER DOCUMENTAL}

Aurélio de Paz Reis, pioneiro do cinema português, era um homem da modernidade. Inicialmente comerciante de flores, logo também se tornou empresário do ramo fotográfico (antes era fotógrafo amador) e proprietário de um comércio de automóveis: dois produtos símbolos do progresso, sinais dos novos tempos. Liberal, democrata, Reis esteve envolvido com o movimento republicano de 31 de Janeiro de 1891 (desencadeado na cidade do Porto). Era um dos quadros da burguesia lusitana, vereador em sua cidade, director do Ateneu Comercial. Não surpreende, assim, seu precoce envolvimento com a arte cinematográfica.

Como era comum na época, suas breves pioneiras películas exibiam cenas do cotidiano, as novidades de um mundo que se modernizava e cuja velocidade a todos assustava, o que inclusive valorizava os mecanismos de captação da imagem: a fotografia e o cinema, novos artefatos do progresso. Em grande parte dos países, como no caso do Brasil, já nesses primeiros filmes podemos encontrar imagens de esporte $^{(10)}$. Na produção de Reis, contudo, não foi possível identificar essa inserção.

As primeiras cenas de esporte do cinema português surgem mesmo na obra de outro importante pioneiro: Manuel Maria da Costa Veiga, que fora inicialmente exibidor, um dos donos do Salão Avenida, uma sala de projeção localizada na Avenida da Liberdade (Lisboa). Envolvido com o ramo de espectáculos (foi proprietário de teatro e constantemente organizava projecções ao ar livre), em 1899 compra uma máquina de filmar e produz Aspectos da Praia de Cascais, onde capta o hábito dos banhos de mar e as actividades de um clube esportivo daquela localidade. Devemos também destacar a presença do esporte nas obras de João Freire Correia, um dos fundadores da importante Portugália Film, construtor do $1^{\circ}$ estúdio cinematográfico de Portugal, grande inovador da arte no país. Duas de suas "proezas" estive- 
ram relacionada ao campo esportivo: em 1908, tentou realizar, sem sucesso, o primeiro filme sonoro do país, utilizando como locação o "Paraíso de Lisboa", notadamente as instalações do ringue de patinação daquele complexo de entretenimento; em 1910, filmou e exibiu apenas 4 horas depois o curta documental Corrida de automóveis na rampa da Pimenteira, sobre uma da mais célebres provas dos primórdios do automobilismo lusitano.

Desses momentos iniciais, no que se refere ao carácter documental das películas, vale ainda citar III Exposição Internacional de Automóveis, Aviação e Sport (1924), por três motivos: a) pela articulação do esporte com outros elementos símbolos da modernidade (carros e aviões); b) por ser o último filme de uma das mais importantes produtoras pioneiras, a Invicta Film; c) pelo uso literal da palavra "sport", aliás ainda na versão em inglês.

Seria exaustivo citar o grande número de realizações desse período nas quais o esporte esteve presente: tanto em curtas-metragem quanto nos cinejornais (bastante comuns durante muitos anos, notadamente antes da invenção da televisão) pode-se encontrar muitas cenas dos primórdios do hipismo, boxe, futebol, turfe, ginástica, automobilismo, ciclismo, remo e mesmo educação física ${ }^{5}$. A prática esportiva foi representada como uma das novidades do mundo moderno, como ocasião de festas, articulada com outros objetos no nascimento de uma "sociedade do espetáculo"(11), como algo cada vez mais valorizado pela população dos mais diferentes estratos sociais. As compararmos tais ocorrências de Portugal com o que se passou no Brasil, pode-se identificar similaridades: a forma de filmar o esporte é aproximada (cenas documentais, expressão de uma nova formação cultural); os responsáveis pelas realizações estavam envolvidos com o nascimento da indústria do entretenimento; a valorização do carácter festivo. $\mathrm{O}$ esporte definitivamente começa a consolidar sua popularidade e a "arte da modernidade" demonstraria isso em suas telas.

\section{O ESPORTE NA FICÇÃO: PRIMEIROS MOMENTOS - COMÉDIA}

Ainda não como o tema central, deve-se ao importante actor Nascimento Fernandes a primeira inserção do esporte em filmes portugueses de ficção. Já gozando de grande popularidade no teatro, onde fazia parceria com sua esposa Amélia Pereira, Nascimento decidiu se dedicar ao cinema, onde se destacaria como um dos grandes comediantes de seu tempo, fundando, em 1918, a Portugal Films. Em 1919, lança Nascimento, sapateiro, onde o futebol é inserido de forma irónica, compondo o quadro de problemas do personagem-chave.

Ainda de autoria de Fernandes, deve-se mesmo destacar a comédia Vida nova, lançada também em 1919. Nessa película, a personagem feminina central, pela qual se apaixona o protagonista (representado por Nascimento), é casada com um ciumento lutador de boxe. O personagem aprende a lutar, desafia o marido e o vence no ring. As reviravoltas da trama contemplam até uma mulher (representada por Amélia Pereira) aprendendo boxe para retomar o amor do personagem central, espancado ao fim pela nova boxeadora.

Por que terá sido inserido o boxe nessa trama? Dever-se-ia à popularidade deste esporte em Portugal? Provavelmente não. Nascimento parecia estar inspirado em outros filmes em que o pugilismo fora incluído de maneira cómica, com o lutador mais fraco, de forma improvável e desajeitada, vencendo o mais forte. Charles Chaplin, por exemplo, já fizera o mesmo em Campeão de boxe, de 1915. Sequências semelhantes futuramente também estariam presentes em Boxeur por amor (1926), de Buster Keaton, em Luzes da cidade, de Chaplin (1931), e Sparring por um dia, de René Clement (1936), entre muitos outros ${ }^{(13)}$.

É com o mesmo intuito cômico que o boxe foi introduzido em outro filme português: Charlotin e Clarinha (1925, de Roberto Nobre), cujo personagem central é claramente inspirado em Carlitos (Charlot). Essa película merece destaque por ter sido a única experiência de direcção de Nobre, um dos mais importantes críticos portugueses de cinema. Nos intertítulos dessa curiosa obra da fase muda, curiosamente só revelada ao público em 1972, há ainda várias referências irónicas a esportistas da época.

Os curiosos filmes de Romão Gonçalves, excêntrico tenor e duble de esportista (membro activo do Club Sport Marítimo), figura polémica da sociedade lisboeta da época, seguem o mesmo tom cómico: Romão, chauffer e mártir, Romão Gonçalves, boxeur e atle- 
ta e Romão Gonçalves, cantor e nadador, todos lançados em 1920. O actor/director, como forma de autopromoção, executa exercícios ginásticos (método Sueco e com halteres) e demonstra sua "habilidade" no automobilismo, no boxe e na natação.

Em 1927, Reinaldo Ferreira, popular jornalista da cidade do Porto, fazendo uso de seu pseudónimo e associado a comerciantes locais, funda a Repórter $\mathrm{X}$ Film. É o próprio Ferreira que escreve e dirige Vigário Foot-ball Club (1927), a primeira vez em que o futebol é o tema central de um filme de ficção em Portugal.

Tendo como actores Alves da Costa, Alexandre Amores, Fernanda Alves da Costa, seguindo a linha de comédia, o filme aborda um tema que posteriormente será retomado por diversas vezes na cinematografia portuguesa, em outros formatos e com outros enfoques: a corrupção no mundo do futebol. A comicidade é garantida pelos personagens exóticos/jogadores que formam as equipes, uma das quais tendo um anão como goleiro.

Para concluir este item, fazemos referência a Bailando ao sol, de António Lopes Ribeiro (1928), uma verdadeira ode a um novo modelo de mulher, que valoriza a vida ao ar livre e cuida de seu corpo com exercícios de ginástica e dança. Mesmo que pareça ser pequeno o espaço do esporte nesse filme, vale o registro já que é a única excepção no que se refere ao carácter cómico que marca a inserção da prática esportiva nessas primeiras ocasiões de sua presença em películas de ficção.

\section{O ESPORTE NOS LONGAS-METRAGEM: CENAS DE UM MOSAICO}

Lisboa, crônica anedótica (1930), dirigido por Leitão de Barros, um dos ícones do cinema português, foi uma grande realização, contando com uma das melhores equipes técnicas até então montadas no país. Este filme é considerado como uma das obras-primas da cinematografia de Portugal.

Uma vez mais vemos a produção portuguesa dialogando com o cinema internacional. Esta película foi inspirada em Berlim, sinfonia de uma metrópole (1927, Walther Ruttmann), que por sua vez desencadeara experiências semelhantes por vários países, como no caso do Brasil com São Paulo, sinfonia de um metrópole (1929, Rodolfo Lustig e Adalberto Kemeny).
Trata-se de um documentário sobre a cidade na transição das décadas de 1920-1930, um panorama do frenesi de uma metrópole e de seus personagens cotidianos. O filme busca capturar a excitabilidade da vida moderna e industrial, exibida de uma maneira esteticamente adequada às novas dimensões culturais em vigor.

Nesse cenário, assim como nos casos alemão e brasileiro, o esporte ocupa espaço relevante na película portuguesa: cenas de automobilismo, ciclismo, futebol, ténis, esgrima, basquete, remo, vela, hipismo. A presença da prática esportiva em um filme que intenta fazer uma "arqueologia" dos novos tempos na capital de Portugal demonstra o já alto grau de inserção da manifestação na dinâmica social do país, sua importância simbólica, sua articulação com as outras dimensões culturais.

Vale ainda destacar o fato de que, ao contrário da maior parte das experiências anteriores, o esporte não foi inserido em um quadro cómico, mas como um dos importantes elementos que compõe o grande mosaico da nova urbanidade.

A prática esportiva voltará a uma comédia em $O$ trevo de quatro folhas, de Chianca Garcia, um dos únicos longas produzidos em Portugal no ano de 1936. Protagonizado pelo já citado Nascimento Fernandes e pelo famoso jogador Waldemar Mota, contando com a especial participação do actor brasileiro Procópio Ferreira, nessa película o futebol é utilizado não só para compor uma série de equívocos comuns em narrativas cómicas, assim como para delinear certos estereótipos que bem servem à tentativa de fazer o público rir, mas que também deixam entrever certas representações culturais: o espanhol como um tipo malicioso e perigoso, o sul-americano como alguém de honestidade suspeita.

Esse modesto filme, de baixo orçamento, tematiza ainda uma questão bastante comum no cinema português, certamente um reflexo de uma tensão cultural mais ampla: até que ponto Portugal é regional, até que ponto é europeu.

Três anos depois, em 1939, o esporte voltará à grande tela, de novo pelas mãos de Leitão de Barros. Em A varanda dos rouxinóis, com o na época famoso ciclista Noé de Almeida ocupando papel de coadjuvante, um dos personagens do triângulo amoroso central, representado por Oliveira Martins, sagra-se campeão 
de uma competição de bicicletas. Entre as cenas vemos flagrantes da importante "Volta a Portugal em Bicicleta", uma das principais provas do ciclismo do país, disputada desde 1927.

O ciclismo voltará duas vezes mais às telas: em Cartas na mesa (1973, Rogério Ceitil) e como tema central de O homem do dia (1958, Henrique Campos), que aproveitou outro momento de popularidade da prática. Exibindo muitas cenas ciclísticas, inclusive da já citada "Volta a Portugal", a trama é permeada pelo fato de que Tó e Patela, rivais nas pistas, disputam o amor de Clara. Actuou como actor Alves Barbosa, campeão de muitas provas nacionais e internacionais, inclusive a "Volta" de 1951, 1956 e 1958. Como curiosidade, esse foi o primeiro longa feito em Cinemascope em Portugal.

O aproveitamento de uma competição esportiva na composição do enredo de um filme já fora antes experimentado em Uma cidade... canção (1946, J. Oliveira dos Santos), cujo pano de fundo são as regatas nacionais realizadas na Figueira da Foz, tradicional local de prática do esporte náutico. Foram produzidas ainda mais duas versões dessa película, uma em inglês e outra em espanhol, de forma a divulgar as belas praias portuguesas em outros países europeus.

No ano de 1947 foi lançado um dos mais importantes filmes da cinematografia de Portugal em que o futebol é tematizado: O leão da estrela, de Arthur Duarte. A história é desencadeada quando Anastácio, torcedor do Sporting Club, desloca-se ao Porto para assistir uma partida decisiva. Nessa que é considerada uma das melhores obras de Duarte, o esporte é inserido no conjunto de costumes que caracterizam a pequena burguesia que habitava os bairros populares das cidades portuguesas. O mesmo Arthur Duarte voltará a incorporar o esporte em Dois dias no paraíso (1957), dessa vez o hóquei sobre patins, aproveitando a popularidade dessa modalidade no momento em que a equipe portuguesa estava entre as melhores do mundo (fora campeã mundial em 1956). Entre as sequências se pode ver inclusive cenas de um jogo entre Espanha e Portugal.

No decorrer da história do cinema português, muitos outros filmes incorporaram cenas de esporte, com sentidos e graus de presença diferenciados. Em
A passagem de nível (1965, Américo Leite Rosa), a prática do golfe ajuda a traçar o perfil dos personagens mais ricos. O automobilismo ocupa importante espaço em Derrapagem (1974, Constantino Esteves). Inserido no âmbito de um movimento de reivindicação, vemos tomadas de esporte em Crônica de emigrados (1979, Manuel Madeira). A esgrima está presente em A sétima letra (1988, Simão dos Reis). O futebol é pano de fundo no recente Tudo isso é fado (2003), uma co-produção Brasil/Portugal, e esteve inserido em O testamento do senhor Napumoceno (1997, Francisco Manso).

Enfim, a presença multifacetada da prática esportiva é mesmo notável, reflexo do seu significativo espaço na sociedade portuguesa.

\section{O ESPORTE COMO TEMA CENTRAL: UM OLHAR CRÍTICO}

Em alguns filmes destaca-se a busca de uma abordagem mais crítica: o esporte já não mais representado dentro de uma lógica de comédia ou romance, nem somente como uma expressão dos novos tempos, mas como representação dos problemas sociais, algo eivado das contradições que compõe a sociedade como um todo.

Em 1947 é lançada uma das grandes referências da presença do esporte no cinema português, Bola ao centro, de João Moreira, primeira oportunidade em que o velho esporte bretão será o tema central de um longa-metragem. Félix Ribeiro(14) o considera como o primeiro filme efectivamente "esportivo" de Portugal:

Os desportos como temas de filmes de ficção não têm, dum modo geral, suscitado o interesse de produtores, a não ser, particularmente, o dos americanos, sobretudo quanto a alguns géneros desportivos, como o "base-ball", o "rugby" e mais especialmente o "Box" (...) Reportando-nos agora a outro género de desporto, o futebol, que sempre foi o desporto-rei na Europa, verificaremos, que nos recorde, que apenas dois exemplos aparecem (...) O outro filme era efectivamente português, com argumento e realização de um novo, o malogrado João Moreira.

Bola ao centro narra a história de um jovem que, desejando tornar-se um jogador de futebol (apresen- 
tado como "desporto violento"), vai de encontro às restrições de seus pais, abandonando emprego e família para ingressar em um clube. Envolvido pelas artimanhas do mundo esportivo, enganado por mulheres interesseiras, corrompido pelas noites em cabarés, acaba fracassando e retorna ao lar e à vida normal. Claramente percebe-se tanto um tom de denúncia quanto uma mensagem moralista, o que chegou a desencadear polémicas com meio futebolístico português da época.

O filme logrou grande sucesso de crítica (as únicas ressalvas foram à ineficiente recriação das partidas de futebol6) e de público, chegando a estrear simultaneamente em três cinemas, algo raro para a época. A despeito das polémicas, trata-se de um bela representação de todas as dimensões que cercam e constituem o espectáculo esportivo. Comenta António Lourenço, em o "Século"(16):

Serve-lhe de moldura o cenário rico de pitoresco, estuante de alegria e vibração dos meios futebolísticos. Há um tão flagrante fundo de verdade na estrutura deste tema que dir-se-ia ter sido copiado da realidade. Diga-se de passagem que este aspecto, revivendo com sutileza circunstâncias conhecidas e debatidas, eleva a obra a um plano de interesse que a torna simpática ao espírito de quantos ambicionem ver resolvido o problema social do futebol.

Também com um tom bastante crítico, Belarmino, dirigido por Fernando Lopes, é lançado em 1964. O enredo central é a vida do ex-boxeador Belarmino Fragoso, sua trajectória pugilística e sua visão de mundo. Aproveitando as contradições e as peculiaridades desse esporte, inclusive do ponto de vista estético, dialogando com as propostas do cinema-direto, da Nouvelle Vague e do Neo-realismo, no contexto do movimento do Cinema Novo português, Lopes insere o lutador no quadro de tensões sociais e urbanas de Lisboa, realizando um dos mais celebrados e premiados filmes da cinematografia lusitana.

Esta película é um produto dos movimentados anos 1960 em Portugal, de uma geração que via nos cineclubes uma alternativa para a organização política e tomada de consciência, algo que dialogava com a agitação social do momento, greves universitárias, mobilizações de esquerda, expressões do desejo de fim da longa ditadura que se abatia sobre o país e fruto do diálogo com as reivindicações juvenis que se alastravam por todo o mundo. Nesse cenário, emergiam novos heróis, representantes do povo em sua luta cotidiana, controvertidos, mais humanos (o que, aliás, os aproxima mais da ideia de anti-heróis). O boxe será mais uma vez utilizado para a discussão de questões sociais, notadamente a falta de opções em meio às injustiças económicas, em "Knock-out" (1968), de Viriato Barreto, rodado em Moçambique com actores, actrizes e equipe técnica daquele país. Lamentavelmente até esse momento não foi possível conseguir maiores informações sobre esta película. O Cinema-Novo português apontará de novo suas câmeras para o futebol em 1971, quando Rogério Ceitil realiza Grande, grande era a cidade, só exibido uma vez em 1972, no Festival de Santarém, sendo logo proibido pela censura. Se antes o velho esporte bretão era tematizado a partir do fascínio que causava na população, Ceitil desconfia que há algo de alienação nesse forte envolvimento. Aparentemente trata-se do estabelecimento de um relação dúbia com o fenómeno, algo muito próximo do que se passou com o Cinema Novo brasileiro(17).

Depois da Revolução dos Cravos, em poucos filmes o esporte foi o motivo central. Às vésperas desse episódio-chave da história portuguesa, destaca-se o lançamento de Eusébio, a pantera negra (1974), dirigido pelo espanhol Juan de Orduña, um documentário sobre a vida e trajectória de um dos mais importantes jogadores do futebol português. Sem grandes qualidades artísticas, essa película foi muito criticada e não teve a repercussão esperada, ainda que o personagem central seja muito interessante. Parece que a abordagem adoptada pelo director estava inadequada ao momento de efervescência política da época. É somente em 1984 que veremos lançado um novo filme inteiramente dedicado a uma prática esportiva: O nosso futebol, dirigido por Ricardo Costa, um documentário sobre a trajectória do esporte mais popular de Portugal, uma discussão sobre seu carácter político e sua ocorrência enquanto "fenómeno de massas". Para encerrar, temos ainda que destacar o festejado e premiado Fintar o destino (1997, Fernando Vendrell), que tem como personagem central Mané, um taberneiro cabo-verdiano que vive em Mindelo, na Ilha de São Vicente, em meio a seu sonho de ter sido goleiro na juventude. As situações ao redor do futebol de 
certa forma são usadas como metáforas para discutir os relacionamentos de Portugal com suas ex-colónias, e nesse quadro o conflito de gerações e a imigração, questões bastante contemporâneas.

\section{CONCLUSÃO}

O relacionamento entre cinema e esporte não deve ser entendido somente a partir das ocorrências em que o segundo foi um tema para o primeiro, mas também a partir dos diálogos intersemióticos que se estabeleceram entre as duas linguagens ${ }^{(18)}$. Da mesma maneira, é interessante investigar algumas "coincidências" de trajetórias, na verdade indícios de outra natureza para entender a relação entre essas duas manifestações culturais.

Por exemplo, é comum a participação de atletas como actores, normalmente em papéis em que podem exibir suas habilidades esportivas. Esse é o caso de John Weissmuller, nadador que actuou no cinema norte-americano; de Max Schmeling, boxeador alemão; do argentino Alfredo Di Stefano, jogador de futebol que actuou no cinema espanhol; e de Pelé, que participou de muitos filmes brasileiros e do famoso Fuga para vitória (1981), dirigido por John Huston. Em Portugal, além dos atletas já citados no decorrer do artigo, podemos ainda lembrar de Nestor Lopes (que atuou em Sereia de pedra, de 1923), Álvaro e Francisco Lyra (Olhos da alma, 1925) e Ruy Cunha (O rei da força, de 1924).

$\mathrm{O}$ fato é que paulatinamente os atletas foram se tornando estrelas, figuras socialmente reconhecidas, e o cinema tanto utilizava tal fama para buscar aumentar a popularidade dos filmes quanto ajudava na difusão e consolidação da imagem dos esportistas. Essa relação é um indício de como o esporte não é uma prática descolada da dinâmica sócio-cultural: seu desenvolvimento está plenamente articulado com o contexto em que se insere, dialogando com todas as peculiaridades de um processo de construção complexa ${ }^{7}$. Também não se deve perder de vista a produção de curtas-metragem, inclusive porque, no caso de Portugal, é nesses filmes que temos encontrado, nos últimos anos, o esporte mais representado. A título de exemplo, podemos citar: $O$ jogo - perder para ganhar (1995, José Manuel Lopes), Vencer a sombra (1996, Paulo Aries/Pedro Madeira), És a nossa fé (Edgar Pêra, 2004), Dies Irae (2004, João Morais Ribeiro), Documento boxe (2005, Miguel Clara Vasconcelos).
Mesmo reconhecendo que a melhor consideração dessas possibilidades pode nos permitir uma análise mais aprofundada, ressalvamos que isso foge ao intuito deste estudo: desenvolver uma cartografia introdutória dos relacionamentos entre esporte e cinema em Portugal, esforço que não parece menos importante, até mesmo por ser base fundamental para futuras investigações. $\mathrm{O}$ resultado apresentado neste artigo já se constitui em um bom panorama, mas reconhecemos o seu carácter introdutório, esperando que possa despertar o interesse de outros investigadores pelo tema.

No caso do Brasil, tem sido possível manter sempre actualizado nosso banco de dados ${ }^{8}$, já que operacionalmente temos possibilidade de acompanhar os progressos da preservação da memória cinematográfica, bem como os novos lançamentos. Além disso, temos realizado investigações fazendo uso desses filmes catalogados.

No caso do banco de Portugal, há duas alternativas para a manutenção da actualização: a) aguardar o lançamento de novos catálogos de filmes, que contemplem a produção mais recente; b) estabelecer acordo de cooperação com colegas pesquisadores portugueses tendo em vista a realização constante de tal tarefa.

Assim sendo, esperamos que este artigo possa ser a primeira de uma série de acções, tanto no sentido de resgate das informações sobre os filmes portugueses em que o esporte esteve presente quanto no sentido de desenvolvimento de estudos históricos ou sociológicos que utilizem essas películas catalogadas como fontes.

\section{AGRADECIMENTOS}

Ao Conselho Nacional de Desenvolvimento Científico e Tecnológico (CNPq)/Brasil e à Fundação de Amparo à Pesquisa do Estado do Rio de Janeiro/Faperj, pelo apoio financeiro concedido para a realização deste estudo.

\section{CORRESPONDÊNCIA}

Victor Andrade de Melo

Praia de Botafogo, 472/810

Botafogo, Rio de Janeiro - RJ

CEP: 22250-040

E-mail:victor.a.melo@uol.com.br 


\section{NOTAS}

${ }^{1}$ Cito aqui La Sortie des ouvriers de l'Usine Lumière (A saída dos operários das Fábricas Lumière). Os irmãos Lumière encontraram a solução para alguns problemas encontrados em uma longa trajetória de tentativas de captação e exposição de imagens em movimento, realizando pioneiramente uma sessão pública, sendo, por isso, por muitos, considerados inventores do cinema(1).

2 Destacamos que os cineastas não "reproduzem" a realidade, mas sim a interpretam, dialogando com o contexto em que suas obras são produzidas, tanto em ficções quanto em documentários. Para uma discussão teórica sobre tal assunto, ver estudo de Burke ${ }^{(2)}$.

${ }^{3}$ Uma das visitas foi realizada pela acadêmica Juliana Garcia, minha orientanda e bolsista de iniciação científica do Conselho Nacional de Desenvolvimento Científico e Tecnológico (CNPq)/Brasil, dentro do conjunto de suas tarefas de investigação. ${ }^{4}$ Para uma compreensão mais aprofundada sobre as potencialidades do método comparado, ver o estudo de Melo ${ }^{(9)}$.

${ }^{5}$ Para maiores informações sobre os títulos, ver o estudo de Matos-Cruz(12).

${ }^{6}$ Uma discussão sobre a dificuldade de filmar o futebol foi procedida no estudo de Melo(15).

${ }^{7}$ No caso do cinema português, é ainda digno de nota que um de seus maiores cineastas, Manoel de Oliveira, teve um forte envolvimento com o esporte em sua juventude (notadamente com o atletismo, com a ginástica e com o automobilismo), ainda que não tenha inserido o objeto em sua produção. Sobre a vida do cineasta, ver o filme Oliveira, o arquitecto, de Paulo Rocha (1993) e os livros de Costa(19) e Machado(20).

8 http://www.anima.eefd.ufrj.br/esportearte/consulta/home.asp

\section{REFERÊNCIAS}

1. Mannoni L (2003). A grande arte da luz e da sombra. São Paulo: Senac/Editora Unesp.

2. Burke P (2004). Testemunha ocular: história e imagem. Bauru: Edusc.

3. Melo VA (2006). Cinema e esporte: diálogos. Rio de Janeiro: Aeroplano/Faperj.

4. Ribeiro MF (1983). Filmes, figuras e factos da história do cinema português - 1896-1949. Lisboa: Cinemateca Portuguesa.

5. Matos-Cruz J (1999). O cais do olhar: o cinema português de longa metragem e a ficção muda. Lisboa: Cinemateca Portuguesa/Museu do Cinema.

6. Matos-Cruz J (1989). Prontuário do cinema português - 18961989. Lisboa: Cinemateca Portuguesa/Museu do Cinema.

7. Cinemateca Portuguesa (1995). Cinemas da África. Lisboa: Cinemateca Portuguesa.

8. Melo VA. Memórias do esporte no cinema brasileira: sua presença em longas-metragem brasileiros. Rev.Bras.Cienc.Esporte, 25(1): 46-59.

9. Melo VA. Por uma história comparada dos esportes. Movimento: $13 / 3$, no prelo (lançamento previsto para setembro de 2007).

10. Melo VA (2006). Cinema e esporte: diálogos. Rio de Janeiro: Aeroplano/Faperj.

11. Debord G (1997). Sociedade do espetáculo. Rio de Janeiro: Contraponto.

12. Matos-Cruz J (1989). Prontuário do cinema português - 18961989. Lisboa: Cinemateca Portuguesa/Museu do Cinema.

13. Melo VA, Vaz AF (2006). Cinema, corpo, boxe: suas relações e a construção da masculinidade. Artcultura, 8(12): 139-160.

14. Ribeiro MF (1983). Filmes, figuras e factos da história do cinema português - 1896-1949. Lisboa: Cinemateca Portuguesa: 561.

15. Melo VA (2006). Futebol e cinema: relações. Rev.Port.Cienc.Desp. 6(3): 362-372.

16. apud Ribeiro MF (1983). Filmes, figuras e factos da história do cinema português - 1896-1949. Lisboa: Cinemateca Portuguesa: 565 .

17. Melo VA (2006). Cinema e esporte: diálogos. Rio de Janeiro: Aeroplano/Faperj.

18. Melo VA (2006). Cinema e esporte: diálogos. Rio de Janeiro: Aeroplano/Faperj.

19. Costa JB (1988). Manoel de Oliveira: alguns projectos não realizados e outros textos. Lisboa: Cinemateca Portuguesa.

20. Machado A (2005). Manoel de Oliveira. São Paylo: Cosac \& Naif. 